Thinking complex interconnections: transition, nexus and Geography

\author{
Tim Schwanen \\ School of Geography and the Environment \\ University of Oxford \\ South Parks Road \\ Oxford, OX1 3QY \\ United Kingdom \\ Phone: +44-1865-285503 \\ Email: tim.schwanen@ouce.ox.ac.uk
}

Paper prepared for:

Transactions of the Institute of British Geographers

Original Submission: 20 February 2017

First Revised Submission: 22 July 2017

Final Submission: 2 September 2017

Published as:

Schwanen, T. (in press) Thinking complex interconnections: transition, nexus and Geography. Transactions of the Institute of British Geographers, DOI: 10.1111/tran.12223. 


\title{
Thinking complex interconnections: transition, nexus and geography
}

\begin{abstract}
More than ever is Geography surrounded by interdisciplinary movements claiming expertise with regard to the interconnections among nature, society and technology. These movements ask questions from Geography and geographers about if and how they can contribute to those movements and what form collaboration might take. This article analyses Human Geography's interactions with research on sustainability transitions since the early 2000s to think through future interactions between Geography and water-energy-food-nexus research. It shows that concepts, ideas, logics and methods have travelled from Human Geography into Transition Studies but that exchange between them has so far been partial and asymmetrical. Arguing that common ideas about how interdisciplinarity can be encouraged might be insufficient to change this situation, the paper develops ideas from Stengers, Whitehead, Foucault and others to explain the relations between Human Geography and Transition Studies in terms of modes of abstraction in an evolving ecology of power relations. It makes a case for slowing down modes of abstraction and proposes some ideas for slow collaborative research on sustainability transitions in contact zones. Implications for how Geography and geographers might engage with interdisciplinary nexus research are outlined.
\end{abstract}

Keywords: interdisciplinarity, sustainability transition, nexus, abstraction 


\section{Introduction}

Recent decades have witnessed the emergence of various interdisciplinary movements concentrating on interconnections among nature, society and technology. The recent academic interest in the nexus of water, energy, food and climate is policy and business driven yet also the latest instalment of a series of movements focused on 'coupled human-environment systems', 'socio-ecological systems' and also 'sustainability transitions'. Originating in the interstices of conventional academic disciplines, research highlighting these concepts has expanded rapidly. Not only has it found domicile in a new field sometimes called sustainability science; it has also travelled into more established disciplines, including Geography. In fact, where previously cross-disciplinary intellectual and political developments such as positivism, phenomenology, Marxism, feminism, the crisis of representation and a (re)turn to materiality were key sources of change in (Human) Geography, the discipline now sees itself confronted by a proliferation of interdisciplinary movements that claim some of the intellectual terrain that has long been dominated by geographers. ${ }^{1}$

As far as the interconnections among nature, society and technology are concerned, geographers have responded to this proliferation of interdisciplinary movements in multiple ways. Some have been enthusiastic, others more cautious or critical (see, for instance, Cote and Nightingale 2011; Lawhon and Murphy 2012; Castree et al. 2014; Castree 2016). In this paper I seek to add to debates about Geography's relations with interdisciplinary movements by reflecting on the questions if and how Geography can contribute to those movements and what forms collaboration might take. To make this broad aim manageable, I will use the recent interactions between (Human) Geography and sustainability transitions scholarship to think through future interactions between Geography and research on the water-energy-food nexus. My argument will be twofold. While (Human) Geography has much to offer in terms of concepts, ideas, logics and methods to the rapidly increasing interdisciplinary research about the interconnections among nature, society and technology, recent experience with research on transitions suggests that diffusion of geographical thought and praxis into nexus research is unlikely to come about naturally or easily. It thus seems that prevailing ideas about how interdisciplinarity can be advanced are not sufficient to encourage greater and more comprehensive uptake of concepts, ideas, logics and methods from Human Geography in transition or nexus research beyond our discipline. I will draw on the thought of Alfred North Whitehead and Isabelle Stengers to suggest that there is a need to slow down interdisciplinary reasoning and practices, and that this can be done by focusing on processes of abstraction.

I begin by discussing interdisciplinarity and outline an approach to understanding the relationships between disciplines and research fields that is informed by the philosophies of Stengers and Whitehead. I will then introduce sustainability transitions and nexus research in greater detail. Juxtaposing Transition Studies - a field in which I have been become involved in recent years through work on the everyday mobility of people - and nexus research may seem odd or even farfetched but is, I suggest, insightful. As elaborated below, there are clear similarities in terms of emphasis on transdisciplinarity, interconnections and complexity but also important differences. Not only is research on sustainability transitions more mature, it is also closer to Human Geography because of its roots in inter alia science and technology studies and lacks most of the natural science traces that characterises nexus research. Thus, if the exchange of concepts, ideas, logics and methods between Transition Studies and Human Geography turn out to be constrained and uneven, it can be expected that stratifications and immobilisations will be larger if, as in nexus research, the difference between social and physical science needs to be negotiated over and beyond the boundary separating discipline from interdisciplinary movement. 


\section{Interdisciplinarity and disciplines}

There are numerous definitions of interdisciplinarity and understandings of how this differs from multi- and transdisciplinarity. Here I follow Barry et al. (2008, page 28) for whom interdisciplinarity denotes a spectrum from multidisciplinarity - cooperation of disciplines whose framings remain largely intact - to transdisciplinarity. The latter term captures a type of reflexive and integrative knowledge production that is oriented at application and addressing societal and environmental problems and involves non-academic stakeholders as active participants (Osborne 2015; Klenk and Meehan 2015). It can be top-down and enabled by supranational organisations, or emerging through bottom-up modes of organisation that are rooted in particular localities. Much of it is akin to mode-2 knowledge production - context-driven, applied and focused on the solving of problems set by the funding agencies rather than initiated by the investigator(s) (Nowotny et al. 2003) - and post-normal in the sense of being focused on profound, systemic uncertainties and on social accountability to stakeholders beyond academia (Funtowicz and Ravetz 1993).

Interdisciplinarity can be pursued for different reasons (Barry et al. 2008) but with transdisciplinarity the most common remains integration. More than once this is underpinned by a presumption of superiority: knowledge production can be improved and made more effective and impactful in addressing societal problems if the inevitable partial and telescopic character of disciplinary perspectives and practices is overcome through some kind of fusion. This presumption is problematic insofar that the inevitably normative and situated criteria by which research is deemed to be improved are either left unspecified or reduced to a narrow utilitarian logic of contribution to societal problem solving. At any rate, there is widespread agreement that the desired integration is difficult to achieve. There now exists a large literature charting the barriers to integration and the processes and conditions that help transdisciplinary research to flourish; Table 1 summarises key insights that have emerged from this literature. It is evident that many conditions militate against integration but many authors draw specific attention to differences in language and discourse and the importance of overcoming these.

\section{$<$ Table 1 about here $>$}

Despite their usefulness, attempts to reduce barriers to integration have been challenged by social scientists, geographers included, who point out the political nature of integration and the productivity of antagonism and friction. While some advocate epistemological pluralism (Castree et al. 2014; Stirling 2015; Adams 2016), others challenge the ontological dimensions of integration (Barry et al. 2008; Donaldson et al. 2010; Klenk and Meehan 2016). The argument in favour of what Barry and colleagues (2008) call agnostic-antagonistic modes of interdisciplinarity is that integration typically means that objects of interest, such as a socio-technical system or the nexus, are posited and taken for granted as matters-of-fact - "mere existence[s]" (Whitehead 1968[1938], page 6) that are "indisputable, obstinate, simply there" (Latour 2008, page 39) and abstracted from their relations and contexts, including the practices and techniques through which they have been enacted. This is both significant and political: once relations and contexts are brought into consideration, those objects become fragile, disputable and multiple - in other words, they become matters-of-concern (Latour 2008) - and alternative ways of being, becoming, thinking and imagining are opened up.

It is for this reason that Klenk and Meehan (2015) advocate a mode of transdisciplinary research on environmental issues that values difference and recognises that the construction of objects like a socio-technical system or the nexus is unequal and power-laden. This is why they advocate the coproduction of knowledge across academic communities and with non-academic stakeholders using methods that foster the generative capacities of friction between versions (Despret 2004) of those 
objects. The hope is that this will open up different futures and trajectories towards greater sustainability and wellbeing (on the understanding that both these terms are matters-of-concern themselves).

The thinking on how to overcome barriers to interdisciplinarity and the call to maximise difference within transdisciplinarity are important and helpful, but various issues can be identified. One is that much of the literature on interdisciplinarity is focused on the social/natural science dichotomy. Due consideration is not always given to further differentiations between and within disciplines and epistemic cultures - specific arrangements and "machineries" that make knowledge construction possible; have distinct technical, social and symbolic dimensions; and that exist and evolve within and across disciplinary boundaries (Knorr Cetina 2009). In addition, the disciplining and disciplinarising tendencies of interdisciplinary movements are not always recognised and explored. It is well-known that "[d]isciplines discipline disciples" (Barry et al. 2008, page 20) and channel research efforts into certain directions, but so do subdisciplines, epistemic cultures and interdisciplinary movements. Likewise, disciples self-regulate (Foucault 1985) as members of subdisciplines, epistemic cultures and research fields with specific concerns, methods, vocabularies and institutions. In other words, a complex landscape of power relations and forces within academia affects research into the interconnections among nature, society and technology. ${ }^{2}$ This is all the more so because, over time, interdisciplinary movements often become institutionalised and turn into 'interdisciplines' ${ }^{3}$ with their own journals, training and education programmes, learned societies, reward structures and career opportunities. Whilst still embedded in longer-standing disciplines and epistemic cultures, Transition Studies has gradually become an interdiscipline; nexus research may be on a similar trajectory.

One strategy for thinking through the complex landscape of (sub)disciplines, epistemic cultures and interdisciplinary movements within which academic research takes place is to turn to Stengers's (2005a, 2010a-b, 2011a) idea of an ecology of practices. Her interest lies in understanding how different practices, particularly those of specific disciplines or research fields, relate to each other and in what this ecology enables them to become. She seeks to understand the "needs, behaviours, habits and crucial concerns" or ethos of a practice and how this influences and is influenced by its oikos, including other practices (Stengers 2011a, page 59). In her Cosmopolitics books she explores the ethos-oikos complex through a focus on the obligations and requirements of a practice (Stengers 2010a-b). Obligations in this context refer to the risks and challenges that a practice imposes on its participants (e.g., practitioners and stakeholders benefitting from its products), and requirements refer to the demands the practice makes on the environment on which depends. A unique constellation of obligations and requirements defines a practice. Thus, if disciplines impose constraints ${ }^{3}$ on research and disciples, then they can be articulated in terms of obligations and requirements. Yet, it is equally clear that disciplines are not the only entities imposing obligations and requirements; sub-disciplines, research fields and epistemic cultures do too.

The emphasis Stengers places on obligations and requirements is useful in the current context. It can help us understand how disciplines and interdisciplinary movements, such as Transition Studies and nexus research, discipline their environments and practitioners and how the latter self-regulate. It also draws attention to the power relations that connect and help to shape disciplines and research fields. Yet, she offers few concrete suggestions how obligations and requirements are to be examined in relation to academic practices; the analysis in the Cosmopolitics books remains at a very general level. I therefore propose to explore such obligations and requirements indirectly, by focusing - as Whitehead did throughout his career as philosopher - on modes of abstraction. Many such modes of course exist within disciplines and fields but there are often also important commonalities in abstraction within a given discipline or research field. 
Whitehead believed that abstraction - selection, simplification, reworking and exclusion - was not necessarily the "malign process of generalisation and simplification through which the complexity of the world is reduced at the expense of the experience of those who live in the concrete reality of this world" (McCormack 2012, page 717). He was obviously aware of the danger of being led "away from the realities of the immediate world" (Whitehead 1967[1925], page 39) but understood abstraction as productive and creative. Elsewhere he suggested that abstraction is part of any instance of creation, not just by or involving human beings (Whitehead 1968[1938], 1977[1929]). Abstraction, on this view, is central to the effects the environment has on a particular entity. It is through processes of selection, simplification, reworking and excluded that a historically constituted and constantly changing environment becomes part of and helps to (re)constitute a particular entity (and vice versa).

For Whitehead (1968[1938]) the specifics of how abstraction unfolds - what is selected, simplified, reworked and excluded, and in what way and sequential order - depended on importance, which is the perspective that is imposed on the environment and that co-evolves with the interests of the entity being considered. The significance that Whitehead attributed to context means that there can be no general rules about when an abstraction is good or not, but he was critical of rigid modes of abstraction that did not adapt to the inevitable change and novelties that occur over time in philosophy, research and the world more generally. Extending Whitehead's arguments, Stengers (2011b) argues that researchers should be vigilant about their abstractions to avoid that they are blindly led by them and that advances in a practice such as transition research or geography are no more than "progress in its own groove [that] prevents straying across country ... and the comprehension of human life" (Whitehead 1967[1925], page 197). Abstraction in research should thus be revisable, adaptable and responsive to the changing contexts of which it is part.

This line of reasoning allows us to appreciate how abstraction can play a generative role in how elements from certain academic practices, such as transition research or geography, become integrated into a practitioner's thinking, writing and other actions. What at a specific moment gets selected, simplified, reworked, excluded and how, depends on her interests and the obligations and requirements of the practice she performs, and all of this can be expected to change over time. The creativity of abstraction is thus mediated by the continuously evolving constellations of obligations and requirements that define disciplines, epistemic cultures and interdisciplinary research fields. Nonetheless, absent from Whitehead's texts is discussion of the political nature of abstraction and how selection, simplification and exclusion are shaped by the regimes of truth and governmentalities - respectively, the dynamics of what is seen as truthful and the shifting constellations of ideas, procedures, techniques and technologies through which practices and practitioners are governed within wider dispositifs (Foucault 1980, 2010). Given that disciplines, epistemic cultures and interdisciplinary movements discipline self-regulating disciples, it is important to consider the politics of abstraction when Whitehead's and Stengers's concepts are used to understand Geography's relationships with interdisciplinary research on the interconnections among nature, science and technology.

\section{Transition and nexus}

\subsection{Multiplicity, creativity and interconnection}

It is important to insist on the multiplicity of the thinking and research on sustainability transitions and the water-energy-food nexus because there are no simple origin stories, developmental narratives or future trajectories, and neither are their clear boundaries between in- and outside. For instance, many narratives of the evolution of Transition Studies highlight how it has emerged out of 
integration of thinking and insights from science and technology studies, history of technology, evolutionary economics and innovation studies (Rip and Kemp 1998; Geels 2002) whilst others also draw attention to the incorporation of crucial inputs from biology and ecology, environmental studies and demography (Rotmans et al. 2001; Loorbach et al. 2017). It is nonetheless still possible to identify key moments and elements that have played a key role in the development of each interdisciplinary movement. Examples include the 2008 World Economic Forum in Davos (WEF 2011) for nexus research, and for sustainability research the incorporation of the concepts of transition and transition management in the fourth National Environmental Policy Plan of the Dutch government in 1990 (Loorbach et al. 2017) and the publication of Geels's (2002) Multi-Level Perspective (MLP) diagram (Figure 1).

\section{<Figure 1 about here>}

Geels's diagram is significant for at least three reasons. First, it has proven profoundly influential by suggesting that fundamental and durable change - a transition - demands the re-alignment of a socio-technical regime, landscape and one or more niches. Here the regime constitutes the set of rules that condition, and are reproduced by, the social practices from which a socio-technical system such as automobility or gas heating emerges; examples of such rules are cognitive routines, shared beliefs, social norms and conventions, regulations, industry standards, protocols, contracts and laws

(Geels 2004). Regimes are dynamically stable; they favour and enable incremental innovations that tend to leave a socio-technical system's basic architecture intact. More radical forms of innovation, transition scholars hold, need the protection of socio-technical niches in which innovations are shielded from regime pressures, nurtured through experimentation and visioning, and empowered so that they become capable of reconfiguring the regime through competition or symbiosis (Smith and Raven 2012). The socio-technical landscape, finally, gathers all the wider contexts and developments over which regime actors have little influence, including demographic shifts, economic crises, and anthropogenic climate change. Geels's original diagram proposes one way in which regimes, niches and landscape interact to generate a transition and this has later been extended (Geels and Schot 2007; Geels et al. 2016). One of its strengths lies in how it foregrounds interconnections, not also among the three levels but also among markets and user preferences, industry, science, policy, culture and technology.

However, and secondly, the diagram needs to be seen as partial and selective, even if it has helped to initiate large numbers of non-innovation scholars into transition thinking. This is not least because it abstracts away geography and most of the insights from biology, ecology, environmental studies and demography that feature more prominently in other articulations of sustainability transitions (Rotmans et al. 2001; Loorbach et al. 2017). Partly because of this, and thirdly, the diagram by Geels - and subsequent reworkings - are not equivocally embraced within the interdisciplinary Transition Studies community. Reservations may be more easily articulated in one-to-one conversations than in peer-reviewed publications but they are not uncommon; the MLP is not as hegemonic within Transition Studies as it may appear at first sight.

\subsection{Interconnection, instability and difficulty}

Nexus thinking has its own diagram (Figure 2), originally included in Hoff's (2011) Understanding the Nexus and now rapidly replicated elsewhere. Whether it will become as influential as Geels's remains to be seen, but the nexus diagram highlights interconnectedness just as strongly - here primarily among water supply, energy security and food securities. To a degree the 'nexus' remains elusive, in part because it has only recently become popular. At the present time, the adjectives 
'unstable', 'difficult', 'technical' and 'governmental' seem most appropriate to introduce nexus research.

\section{<Figure 2 about here>}

Instability is evident from the naming; a survey of the interdisciplinary literature reveals a range of sequences and differences in what is in/excluded. The term water-energy-food nexus clearly dominates but permutations and alternatives can also be encountered, including water-energy-landfood nexus, climate-energy-water nexus, water-soil-waste nexus, climate-energy-land-water nexus, and simply nexus. It is tempting to read this variability as a sign of immaturity and assume that ultimately one term will prevail. However, it is also possible to understand the heterogeneity as indicating that which really matters is interconnectivity; what is interconnected and how is perhaps slightly less important. Thus, Mohtar and Lawford (2016, page 194) claim that "the WEF nexus approach ideally begins with an interrelated system and then notes the two-way relationships between water, food, or energy and the other resources", although many others argue that water is at the heart of it all (Allouche et al. 2015; Wichelns 2017). Yet instability also goes beyond naming. Understandings of the nexus are plural, variable and ambiguous and this "prevent[s] one from stating clearly what constitutes a nexus approach or nexus analysis" (Wichelns 2017, page 113; Cairns and Krzywoszynska 2016).

It is also widely agreed that the nexus is difficult, not only in terms of policy development and implementation but also as an object of thought. Thinking interconnections across domains or systems is difficult, the argument goes, because of the specialisation and fragmentation of science. For instance, a recent Delphi-method study among experts at the U.S. Global Change Research Program demonstrated the difficulty of identifying research priorities that encompassed the full energy-water-land-climate nexus: "[m]ost people are expert in one or two topic areas and so are able to identify with relative ease topics that cover individual sectors or perhaps two sectors ... [w]e saw far fewer topics that hit three sectors and very few that touched all four elements" (Faeth and Hanson 2016, page 124). There is also a scalar dimension to the difficulty of researching the nexus. In research, the focus on the planetary scale that dominates much of the nexus discussion outside academia is often scaled down to the national or sub-national level (e.g., Foran 2015; Howarth and Monasterolo 2016; Yang et al. 2016) to make analysis more tractable. In addition, Leck and colleagues (2015) point out that data and modelling constraints mean that empirical analyses often consider two elements and two-way interactions only.

It is not surprising, then, that to date much research outside Geography has been technical in nature, focusing on the construction of new model systems and coupling of previously existing sector-focused models (e.g., Bazilian et al. 2013; Endo et al. 2015; Chang et al. 2016; Yang et al. 2016). Mathematical modelling and computer simulation do play a role in Transition Studies, but are much more common in nexus research and there often underpinned by methodological and epistemological frameworks originating in the natural sciences. Hence, while much nexus research aspires to be post-normal and transdisciplinary, there is also a lot of work that remains within a conventional model for stakeholder interactions that seeks to separate fact from value. Here, academics and scientists offer putatively neutral, a-political information that will allow others politicians, policymakers, businesses - to make decisions that help to increase the efficiency of resource allocation. For, unlike Transition Studies' emphasis on radical system transformation, it is in terms of increasing efficiency and optimisation and securitisation of existing systems that the nexus is often framed as a governance problem. For Allouche et al. (2015, page 621) this framing reflects a "scarcity crisis narrative" promoted by a conglomerate of business and political elites. This narrative holds that population growth, urbanisation, climate change, political instability and price volatility are culminating into unprecedented crises in water, energy and food availability and tradeoffs, 
which are best overcome through a paradigm of control and ecological modernism's emphasis on technological innovation, better governance and greater market efficiency.

A critical social science literature has nonetheless emerged, challenging this framing of how the nexus should be governed. This work highlights such issues as siloed government departments and agencies, fragmented responsibilities, legislative and regulatory barriers, inattention to power structures and social distribution (who gains, who loses? Where? How?), and inability to deal with complexities and uncertainties in decision making (Pittock et al. 2013; Leck et al. 2015; Allouche et al. 2015; Cairns and Krywozynska 2016). Geographers are playing an important part in this, as they also did in the thinking on the governance of sustainability transitions (Sections 4.1).

\subsection{Complexity}

Transition and nexus research share more than this, or indeed an emphasis on interconnectivity and a commitment to transdisciplinarity. They are also linked through roots in complex systems theory. Rotmans et al. (2001) are clear on this as regards sustainability transitions, which they imagine as non-linear phase shifts from one dynamic equilibrium to another, even if they argue that transition is a sociological concept that stems from biology and demography. Kemp et al. (2007) draw on the concepts of punctuated equilibrium and, following Geels (2004), co-evolution as the scientific basis of the transition management approach; Loorbach and colleagues have advanced this grounding of transition management in thinking from physics, biology and ecology (Rotmans and Loorbach 2009; Loorbach et al. 2017). The nexus literature is equally suffused, animated and shaped by complex systems theory. This is evident, for instance, from a recent discussion of "key elements" (Howarth and Monasterolo 2016, page 54) defining the nexus, such as uncertainty, nonlinearity, feedbacks and emergence - all of which also feature prominently in research on transitions.

There are, however, subtle differences between the two interdisciplinary movements, and indeed within each. Discussions of complexity in the nexus literature have on balance a more natural science orientation than in transition scholarship in which much greater attention is directed towards complexity in institutions, governance and power relations (Loorbach et al. 2017). Still, it is not only nexus research and thinking that is often post-political (Mouffe 2005). The foreclosing of dissent and radically different imaginings of the future through a privileging of expert management, markets and consensus can also be found in some strands of transition scholarship, including part of the transition management literature. Other strands have nonetheless recognised the importance of fostering the political (Seyfang and Smith 2007; Loorbach et al. 2017) and this is another area where insights from Geography have influenced Transition Studies.

\section{Transition and Human Geography}

Having laid the groundwork for thinking through the relationships between Geography and interdisciplinary movements focused on the interconnections among nature, society and technology in the past two sections, I will now concentrate on the interface between transitions research and Human Geography before returning to nexus research in the next section.

\subsection{From first encounters to asymmetries}

Geography's first encounters with transitions research go back to around 2000. Since then transition concepts have moved into the discipline along different trajectories crafted out of the embodied 
practices of specific individuals, including Bernard Truffer (Hoogma et al. 2002; Truffer 2008), Gordon Walker (Shove and Walker 2007; Walker and Cass 2007), James Murphy (Rock et al. 2008), Lars Coenen (Coenen et al. 2010), Mike Hodson and Simon Marvin (Hodson 2008; Hodson and Marvin 2009), and Harriet Bulkeley (Lovell et al. 2009; Bulkeley et al. 2010). These individuals were all engaged in interdisciplinary research over the 2000s, they were routinely publishing outside Geography's core journals, and more than half were employed at interdisciplinary institutes. All also have a long-standing interest in innovation, technology and/or climate change governance.

Yet, their discipline and the sub-disciplines they identify with have also imposed obligations on the research they were involved in, and at least two types can be identified. Firstly, their training and disciplining-cum-self-regulation meant they foregrounded emplacement and the demands for "the earthly materialities of place" that transitions make (Brown et al. 2012, page 1620). They started asking questions about how sustainable transition dynamics affected, and were mediated by, processes that were characteristic of specific regions (Hodson 2008; Truffer 2008), cities (Hodson and Marvin 2009, 2010; Bulkeley et al. 2010) and places (Murphy 2015) beyond the national level historically the dominant focus in Transition Studies. This in turn directed attention to questions of scale (Hodson and Marvin 2009; Coenen et al. 2012) and translocal and transnational networks (Hodson and Marvin 2009; Bulkeley et al. 2010). Secondly, their training and disciplining-cum-selfregulation raised pertinent questions about politics and power (Shove and Walker 2007; Hodson and Marvin 2009). Similar concerns had emerged elsewhere previously (e.g., Meadowcroft 2005) but what geographers added were questions about spatial and scalar politics.

Obligations were accompanied by requirements. Concepts like transition, socio-technical system and regime had to be able to fulfil the demands made by Geography - and also Economic Geography, Urban Studies, etc. - and in some instances assembled empirical materials. Together, obligations and requirements ensured that for geographers transitions were and remained - arguably until this very day - matters-of-concern rather than matters-of-fact, triggering specific modes of abstraction. They began to compose different versions of the objects populating the transition literature. On the one hand, they offered alternatives to the until recently dominant practice in the latter to abstract away from dynamics at sub- and supranational scales and to pay only limited attention to innovations in which technology, market-based diffusion logics and/or private or public sector actors are only of secondary importance. On the other hand, the practices involving the aforementioned geographers inevitably selected, simplified, reworked and excluded in other ways. For instance, abstracting differently meant sacrificing the prospect of producing a rather neat typology of transition pathways (e.g., Geels and Schots 2007) that can be applied in many contexts and with the potential to exert significant impact beyond academia. Disciplinarisation implied ontological and epistemological differentiation.

Responses to the percolation of transition thinking into Geography have proliferated since 2010 and exhaustive discussion of all developments is beyond this article. They can, however, be represented heuristically by a triad with dismissal, addition and rethinking as its extremes (Figure 3 ). The resulting two-dimensional, inevitably abstract field can be used to position responses - i.e., specific studies and or research projects - as points, lines or fields themselves. ${ }^{4}$ Dismissal in pure form is rare, at least in the published literature (but see Temenos et al. 2017); it can sometimes be encountered at conferences but, in my situated experience, is usually articulated in informal conversations.

\section{<Figure 3 about here>}

Addition is much more common in the published literature and comes in varieties and gradations. Some work remains very close to the work by leading innovation scholars but other research moves further away. A comprehensive overview of additive scholarship by geographers is offered by 
Hansen and Coenen (2015) who single out bringing place specificity to the transdisciplinary literature on sustainability transitions as Geography's biggest contribution: its practitioners have, often in collaboration with scholars who would not self-identify as geographers, highlighted the role of a wide range of geographical factors and processes mediating transition processes. These include urban/regional visions and policies; often privatised, material infrastructures, localised institutions, norms and values; locally specific natural resource endowments; local technology and industry specialisations; and local market formation. Interestingly, Hansen and Coenen also question the usefulness of a focus on place specificity if there is no progression towards generalisable knowledge:

\begin{abstract}
"There is a risk that such analyses simply observe geographical specificity and establish differences in transition dynamics as an empirical matter-of-fact without engaging with the undoubtedly daunting task of fully explaining such differences. This in turn may unduly limit the contribution of geographical analysis to sustainability transitions to that of topical contrivance: of interest to geographers but with limited reach beyond" (2015, page 105 , emphasis added).
\end{abstract}

From my own inevitably partial and situated interactions with transition researchers I recognise the sentiment articulated here. I have, for instance, been asked the dreaded 'so what?' question when presenting my own research analysing spatial differentiation in transition trajectories in people's everyday mobility (Schwanen 2015, 2016). Not only is place specificity simply to be explained away by more universal processes and events for most scholars trained in disciplines imposing other constraints and requirements than Geography does; the sort of explanations that our discipline tends to offer also are at best half-convincing to many of them. My hunch is that additive geographical research published or undertaken since late 2014 - where Hansen and Coenen's overview stops - has not overcome these sentiments among practitioners from other disciplines either. I write this most emphatically not to call for more universalising theory by geographers but to highlight the uneven, power-laden ecology in which Geography and Transition Studies interact.

There is also a vibrant body of geographical scholarship that has actively sought to rethink the concept of sustainability transition. Prominent here is research that is to varying degrees inflected by political economy and political ecology thinking (e.g., Hodson and Marvin 2010; Lawhon and Murphy 2011; Bulkely and Castán Broto 2013; Newell and Mulvaney 2013; Bulkeley et al. 2014; Newell and Phillips 2016). Analysis of citations of selected publications in this vein offers insight into modes of abstraction - what has been selected, simplified, reworked and excluded, and how - as part of the uptake of geographical concepts, ideas, logics and methods by scholars who tend not to self-identify as geographers. Table 2 offers details for selected papers but several more general conclusions can be drawn. The good news is that geographers' work has influenced transdisciplinary research on sustainability transitions in different ways and with varying levels of intensity. This influence takes time to manifest itself, in part because of the ways in which academic publishing works and the very fact that, even in the digital age, information is not consumed everywhere instantly. It is therefore tempting to expect that more geographical concepts, ideas, logics and methods might be absorbed into transdisciplinary thought and practice in due course.

\title{
$<$ Table 2 about here $>$
}

There are, however, significant asymmetries in the mobility of concepts, ideas and logics, and it is not obvious these will dissolve in future. On balance geographers rethinking research on transitions in line with their discipline's obligations and requirements are influenced more profoundly by transition scholars than that the latter are influenced by geographers' work. Moreover, inherited from geographers' published texts are often only what the geographical community would consider elementary ideas; the levels of simplification and reworking that facilitate mobility tend to be very 
large. There is, then, no necessary relationship between what many in Geography would qualify as world-leading research and influence in the wider interdisciplinary literature. Fulfilling the obligation of working at the 'cutting edge' of geographical thought and praxis can go hand in hand with exclusion and gross simplification ${ }^{5}$ in the context of transdisciplinary research on transitions.

This tension can also be observed in other ways. Geographers have undertaken innovative work on pre-figurative community initiatives seeking to enact socially just transitions to a more sustainable, low-carbon and post-capitalist society, such as the Transition Towns movement, eco-developments and related experiments (Chatteron and Pickerill 2010; Aiken 2012, 2016; Mason and Whitehead 2012; Chatterton 2016; Barr and Pollard 2017). Yet, this literature has had limited influence on the now burgeoning scholarship within Transition Studies on grassroots innovations (Seyfang and Smith 2007). This is arguably why a recent systematic review on grassroots innovations (Hossain 2016) entirely disregards the wider geographical literature on Transitions Towns and eco-developments, limiting itself to what I consider additive geographical research on community initiatives (Feola and Nunes 2014; Longhurst 2015). To an extent the disregard for the work by Chatterton, Aiken and colleagues reflects that most of it engages at best tangentially with the MLP and wider transition literature (but see Chatterton 2016; Barr and Pollard 2017). This wider geographical literature on community initiatives is nonetheless directly relevant to Transition Studies, not least because it refuses to buy into the already-hierarchical ontology that the very term grassroots innovation implies and offers alternative logics and vocabularies to the notion of up-scaling that pervades MLPinfected reasoning - for instance, by drawing on Deleuzian concepts of the rhizome and micropolitics (Chatterton 2016).

The tension can also be identified in relational geography critiques (Murphy 2015; Affolderbach and Schulz 2016) of transition thinking and especially the MLP. Now, the term 'relational' is used too often and too loosely in Geography but the conceptual purchase of highlighting the relational and contingent constitution of niches and regimes has been articulated succinctly by Affolderbach and Schulz (2016, page 1952):

"[a] relational perspective questions the hierarchies and logics of the multi-level perspective where innovations are clearly situated within contained niches ... [It] dissolves the clear boundaries of niches and regimes, changes the relationship between different levels and disconnects the alignment and hierarchy between distinct levels and spatial scales. Even further, if transition processes are understood as assembled or simultaneously co-produced by agents at multiple scales, we need to question the origin of innovations and inherently the role of 'niches' as test beds".

And yet I have also experienced the difficulties of explaining a relational conception both of niches and regimes and of space more generally to sustainability transition scholars with whom I have interacted. Absolute and network understandings of space are now common in Transition Studies but more complex and nuanced conceptions of spatiality and spatial dynamics remain rare (but see Sengers and Raven 2015). The sort of thinking on space and spatiality advanced by authors as diverse as Lefebvre (1991), Thrift (2008), Massey (2005), or Harvey (2009) remains easy to exclude from transdisciplinary research on transitions, perhaps because those thinkers refuse to separate space from time and often foreground questions of contestation, politics and uneven development. The criticism that Transition Studies fails to consider power and politics has been addressed in various ways over the past decade (Avelino and Rotmans 2009; Geels 2014; Raven et al. 2016), but questions remain as to whether efforts have gone far enough. Little attention has been given to the idea that contestation, politics and uneven development can be effectively analysed by focusing on dynamics in geographical scale; territoriality; place; and the power-laden mobilities of initiatives, people, ideas, techniques and expertise (Bridge et al. 2013; Murphy 2015; Affolderbach and Schulz 
2016; Schwanen 2016) - i.e., by fulfilling one of Geography's more important obligations. There have been several publications by transition scholars considering transnational linkages in niche innovation and globally distributed networks of sustainability experiments (e.g., Hansen and Nygaard 2013; Wieczorek et al. 2015), but these have ultimately different objectives. In line with their field's obligations, those scholars' interest lies in better understanding what encourages and facilitates innovation and transition dynamics rather than contestation, politics and uneven development.

The fact that selective diffusion of concepts and ideas from Geography into transdisciplinary research on transitions is replicated across different strands of research may reflect processes of disciplinarisation within Transition Studies. This young but rapidly expanding practice is undergoing academic institutionalisation and community formation and thus boundary formation, and the disciplining of self-regulating practitioners these processes entail has generated collectively sanctioned or at least preferred modes of abstraction and specific obligations for those practitioners. The key requirement that Transition Studies as interdiscipline is imposing on Geography and its practitioners is that their concepts, ideas and logics must not stray too far from common sense thinking about space, not contain too much 'jargon' (from the perspectives of Transition Studies), and be broadly compatible with the philosophical and methodological underpinnings of the MLP and other frameworks advocated by leading transition scholars.

\subsection{An urban turn?}

This conclusion can be extended to transition research focused on cities, but only up to a degree. There has been substantial exchange of concepts, ideas and logics between Urban Geography and Transition Studies since the latter embraced Urban Age discourse and the leitmotiv of the city as the quintessential space for innovation and experimentation with low-carbon practices, technologies and supporting institutional arrangements. Multiple narratives regarding the uptake of thinking from Urban Geography in Transition Studies can be put forward. Pessimistic storylines revolving around deficiency, shallowness and non-uptake can be placed on one end of a spectrum; optimistic versions highlighting increased engagement and cross-disciplinary learning due to transdisciplinary collaborative research projects and the formation of a contingent of early career researchers specialising in urban transitions occupy the other end.

A more optimistic position is supported by the observation that the transition literature has come a long way in a short time-span, from Geels's (2010) argument - itself more a response to work by geographers and urban scholars than reflecting an intrinsic interest in the urban - that there are no inherent reasons for a focus on cities, via the emergence of a sustainable urban transformation (SUT) literature (McCormick et al. 2013), to the current interest in urban experimentation and cities as sites that are uniquely suited to transition management and grassroots innovation (Loorbach et al. 2016; Wolfram 2016). Moreover, geographers such as Harriet Bulkeley, Lars Coenen and James Evans have recently collaborated with transition scholars in dedicated projects that have extended the thinking on urban experimentation in ways that are world leading in both Geography and Transition Studies (Bulkeley et al. 2016; Evans et al. 2016).

There are nonetheless two reasons for caution. Firstly, concepts, ideas and logics from Urban Geography are still engaged selectively in the wider transition literature. Empirically oriented research on urban climate change governance (Bulkeley 2010) and social innovation in cities (Moulaert et al. 2010) has been taken up in rather superficial ways, and theoretical thinking that has proven deeply influential in Urban Geography (Lefebvre 1991; Roy 2009) is acknowledged rather than fully engaged. Beyond Geography, work on policy mobilities (e.g., McCann and Ward 2013) has 
so far only been considered by transition scholars who have since actively collaborated with geographers (Sengers and Raven 2015).

Still other thinking remains disregarded altogether, as is the case with both the work on planetary urbanism (e.g., Brenner 2013) and post-colonial attempts to 'world' or 'provincialise' urban research (e.g., Roy and Ong 2011; Sheppard et al. 2013). The thinking by Brenner and colleagues seems particularly germane to Transition Studies. This is because their Lefebvre-inspired approach not only allows resistance and politics to be examined and theorised much more fully and deeply, but also insists on conceptually separating the empirical category of the city from the theoretical notion of the urban. It thereby enables modes of abstraction inclined towards theoretical generalisation whose ethos is at least commensurate with that of the MLP and wider transition theory. Committing to the city/urban distinction means that the argument that cities matter because they are the empirical sites where complex systems meet, mingle and interfere is no longer adequate; it requires theorising how the urban as transformative potential is constitutive of transitions under capitalism. Accepting this premise will fundamentally reconfigure the conditions for the diffusion of concepts, ideas and logics from Geography into Transition Studies and demand new modes of abstraction from transition scholars.

The thinking on worlding and provincialisation holds equal but different potential given that Transition Studies has begun considering transition dynamics beyond the global North (e.g., Romijn et al. 2010; Wieczorek et al. 2015). This work has engaged with insights from development studies but neither with post-colonial thinking on the ordinary city (Robinson 2006) nor with critiques of the neo-colonial relationships between theory and the field according to which sites scattered across the South effectively produce data for theories formulated in northern academic institutions (McCann et al. 2013). Embracing the worlding thesis would mean moving beyond adapting analytical frameworks such as the MLP or transition management to theorising innovation and transition dynamics in Africa, Asia and Latin America in their own right using new, or at least radically reconfigured, concepts that potentially draw on local knowledge traditions and/or emerge from collaborations with local co-producers. Geography is by no means the only discipline to have worked with local knowledges and experimented with co-productionist methods, but many of its practitioners are well versed in provincialising their own assumptions, concepts, techniques and practices and thus abstracting differently. Cross-fertilisation of their experience with research on transitions would again reset the conditions for the exchange of concepts, logics, methods and practices between Geography and Transition Studies and open up new trajectories for crossboundary collaboration.

Secondly, there are significant path dependencies in the abstractions by transition scholars that constrain the uptake of concepts, ideas and logics from Urban Geography. Geels (2010) identified three potential roles for cities in transition processes: as important actors engaging in visioning processes and offering specific types of protection to innovations, as early seedbeds where innovations can be demonstrated and tested by different actors, and as being of limited significance. This distinction has become influential within the SUT literature. For instance, recent research on transition management has used the first two of Geels's roles - the city as actor and as seedbed - as both justification for its city orientation (Loorbach et al. 2016) and starting points for the elaboration of new tools, such as the Urban Transition Lab (Nevens et al. 2013). The roles defined by Geels are important but they also risk turning cities into both passive receptacles and internally homogenous agents with shared interests.

More generally, the SUT literature tends to enact the city in specific ways. Differences notwithstanding, there are several path dependencies in abstraction that are at odds with current practice in most of (Anglophone) Geography. Two of these undergird the matter-of-fact versions of 
the city as a container in which actions and processes unfold and as a concentration of people, resources, materials, etc. characterised by physical proximity. The third path dependency is evident from the idea of the city as an adaptive complex system which reflects both wider scientific discourses about cities and Transition Studies' indebtedness to complex system theory, physics, biology and ecology. As Figure 4 suggests, differences and tensions between the versions of cities enacted by these three fundamental abstractions of the city are negotiated and resolved by turning cities simultaneously into intersections of complex systems - systems of systems - owing to spatial proximity and concentration, locations in which problems and opportunities as well as barriers and inertia are concentrated, and into physically bounded spaces. As far as urban networks are considered, relations between cities are imagined as interaction between pre-existing, discrete elements instead of as the processes through which cities are configured and change.

\section{<Figure 4 about here>}

My concern is not so much whether the abstractions and versions of cities circulating through the transdisciplinary transitions literature are correct but over the effects they generate. Not only are these versions directing attention away from the tensions, contradictions, inequalities, exclusions and contestations that for many urban geographers characterise cities and the urban; they also seem to impose the requirement on Urban Geography and its practitioners to develop concepts, ideas and logics that are broadly compatible with complex systems thinking if geographers want their research be taken up in interdisciplinary research on urban transitions. This highlights how collaborations across (porous) boundaries occur in ecologies conditioned by complex power relations.

\subsection{Where next?}

The rapid evolution of Transition Studies as well as its practitioners' willingness to experiment and respond to critics should be appreciated. There will be further incorporation of concepts, ideas and logics from Geography, just as Geography will adapt to accommodate research on transitions. This is no guarantee, however, that the previously observed asymmetrical exchange and the very selective incorporation of what for many geographers are basic concepts, ideas and logics will be overcome.

To me, the observed asymmetries and selective incorporation are problematic, not because Geography is superior but because diversity brings benefits: geographers don't know better, but they do know differently and can therefore help to imagine, think and enact different futures. Nonetheless, I also believe that more is needed to reconfigure current modes of abstraction than the epistemological and procedural strategies summarised in Table 1. Those strategies are very important but many are insufficiently attuned to the ecology of power relations in which disciplines and research fields develop. They also often operate on longer time-scales than those over which developments in transition and nexus research unfold. Moreover, those strategies may not pre-empt the risk that matters-of-concern - for instance, what is a sociotechnical system? What is a city? - are treated as matters-of-fact. At the same time, harnessing agnostic-antagonistic modes of interdisciplinarity (Barry et al. 2008) and engaging in methodological experiments (Stirling 2015; Klenk and Meehan 2016) risk what Bernstein (1988) called fragmenting pluralism (see also Barnes and Sheppard 2010). This is a situation in which researchers communicate within narrow, homogenising epistemic communities and become more or less isolated from others working on similar issues. My own experience suggests this risk is particularly pertinent in areas, such as transport and energy, where many researchers have a strong desire to generate policy-relevant knowledge. I consider fragmenting pluralism undesirable as it might solidify boundaries between 
Transition Studies and Geography to such an extent that only shallow and simple concepts, ideas, logics and methods travel between them.

A promising way forwards, certainly in the short term, is collaborative research that brings together diverse practices and practitioners from Geography and Transition Studies (especially if there is also a mix of epistemic cultures, career stages, genders and other social differences). As Peter Galison (1997) has argued, meaningful exchange between divergent academic practices is best coordinated locally rather than globally, and the previously mentioned collaborations around questions of urban experimentation (e.g., Evans et al. 2016) exemplify the benefits from local coordination of research practices in a trading zone. Galison $(1997,2010)$ developed this metaphor to characterise the practical ways by which communication in science occurs across Kuhnian paradigms through the development of inter-languages. Others have since developed these ideas by considering the role of materiality, skills and tacit knowledge, and power differences (see the chapters in Gorman [2010] for elaboration). Galison's metaphor has appeal because it understands trading zones as always-in-themaking, contingent and emergent and means that no standard recipes for their creation are on offer. Whilst effectively deployed in pleas for improved communication within Geography (Barnes and Sheppard 2010), the metaphor is less suited to the problem I want to address. This is because Galison (2010, page 32) understands trade as the incomplete coordination of research practices that strips away meaning and memory. This incompleteness offers welcome flexibility but also places the trading zone metaphor at risk of co-optation by the neo-liberalised university and research funding landscape with its fast-paced, volatile conditions for transdisciplinarity. Treading in Galison's footsteps may marginalise Whitehead's vigilance over modes of abstraction, sidestep the importance of obligations and requirements of disciplines and epistemic cultures, and perpetuate asymmetrical exchanges among disciplines and research fields.

The question thus becomes how durable and inclusive zones of interaction between Geography and Transition Studies can be created that can persist beyond the lifetime of short-term research projects and enable the symmetrical exchange of concepts, ideas, logics and methods. The answer, I believe, lies in slowing down of collaborative research. Other geographers have used this term recently but to different ends (Whatmore 2013; Mountz et al. 2015; Lane, 2017). Like Whatmore and Lane, I follow Stengers (2011b) for whom slowing down is less about reducing the speed of research and academic life than about reworking scientific creativity by revising modes of abstraction. Stengers's (2011b) approach is a form of resistance against the "knowledge economy," the contemporary neoliberal configuration in which much academic research takes place, often in partnership with industry, and with a narrow focus on questions that are relevant from commercial or policy perspectives. She urges scientists to understand the world not as messy realm of competing value systems from which research should abstract to arrive at transcendental and disinterested truths but as an inevitable condition they have to appreciate and learn from. They should develop research practices that maximise friction by allowing competent colleagues and nonacademics to object and induce other modes of thinking. Adopting Stengers's propositions will help researchers not only to "stray across country" (Whitehead 1967[1925], page 197) by addressing other - typically value-laden and context-specific - problems, but also to move beyond their own groove and develop more revisable, adaptive and responsive abstractions.

Stengers's arguments are oriented towards natural scientists; questions can be asked about their novelty in social science contexts. Her aims are also different from mine, but two key insights in light of my objectives can be derived from her writings on slowing down research and reasoning (Stengers $2005 \mathrm{~b}, 2011 \mathrm{~b}$ ). One is that subjecting modes of abstraction to scrutiny can help geographers and transition scholars to reason differently and turn matters-of-fact into matters-of-concern. This is because concentrating on abstractions can induce a form of reflexivity that Foucault called problematisation by thought (Rabinow 1994). Thought is here a reflective action that "allows one to 
step back from this way of acting or reacting, to present it to oneself as an object of thought and to question it as to its meaning, its conditions, and its goals" (Rabinow 1994, page 117). Foucault (2010) was optimistic about thought's generative capacities: even if interlocutors are entangled in uneven power relations, the uncertainties induced by thought unhinge the habitual entanglements of cognition and action in research praxis, thereby opening up a space for the emergence of new modes of abstraction.

The second insight is that slowing down reasoning complicates the notion of a straightforward solution to the issue of asymmetric exchange of concepts, ideas, logics and methods between Geography and Transition Studies. Stengers (2005b) cautions that practitioners addressing an issue should not assume they understand a situation or event in the same manner as others. She urges them to try to accommodate the idiotic - that which makes no sense in the context of the consensual interpretation of a situation or issue and which subverts prevailing meanings through, for instance, irony, distraction, refusal or disruption (Michael 2012). ${ }^{6}$ The challenge, then, is to allow oneself to be affected by the idiotic and to replace standard recipes with open-ended suggestions.

Based on earlier experiences, ${ }^{7}$ । propose an open-ended and necessarily general three-pronged strategy for collaborative research involving geographers and transition scholars rather than a readymade solution. The particulars of how to slow down reasoning need to be worked out locally but might involve collaborative analysis of enacted abstractions, historicising and collage over a series of intensive dialogues. A useful point of departure might be making an inventory of different versions of a concept or methodological practice and analysing what is included, simplified, reworked and excluded in those versions. Interlocutors' interests and shared notions of importance may guide the selection of concepts or practices. The discussion in previous section suggests that socio-technical system, city and experimentation as well as the examination of power relations or interactions between spatial scales are likely candidates for collaborative analysis.

The analysis of the abstractions characterising different versions can be enriched by the adoption of an explicitly historicising orientation to trace the inherited elements within those versions of the concept(s) or practice(s) through space and time. The result would be a time-geographical genealogy: Where do those versions come from? How have their elements been reworked? How have trajectories of inheritance been shaped by the obligations and requirements of disciplines and epistemic cultures, as well as by wider regimes of truth and governmentalities? Doing this would improve understanding and appreciation of why, for instance, the urban is understood so differently by urban geographers and researchers from other disciplinary backgrounds working on urban transitions.

Further moving beyond established grooves would result from creating a collage by juxtaposing and overlaying relevant versions of a concept or methodological practice. This step will not only multiply the uncertainties generated by the first two stages and so further stimulate experimentation with new modes of abstraction. It will also encourage participants to work with elements from earlier versions of a concept or methodological practice, which will have changed by their inclusion in the collage. This working with partially pre-existing, partially new elements is useful given that multiple academic disciplines now recognise that innovation entails putting such elements together in new configurations (Arthur 2009; Urry 2012; Schwanen 2015). Collage may induce or intensify problematisation by thought and open up a space for a collective assessment of the contribution that alternative, so far marginalised concepts, ideas or methods from a particular (sub)discipline or field can make to the understanding of transition processes by others. In this way ideas from, say, the planetary urbanism literature could be introduced and absorbed into the thinking of nongeographers working on urban transitions. 
Yet, it will be crucial to remain attentive to the idiotic in the form of irony, distraction, refusal and disruption by researchers from other disciplines or fields. Particular concepts, ideas, logics and methods should not be plugged as ready-mades; they will have to be adapted and hybridised to greater or lesser degree, and may even have to be dropped altogether. What works and what doesn't will need to be worked out along the way.

These necessarily broad suggestions are not intended to create identical abstractions across disciplines, epistemic cultures or research fields; all have specific obligations and requirements. They rather seek to produce more adaptable, revisable and responsive modes of abstraction in each through the creation of contact zones rather than trading zones. I use the contact zone metaphor here in a similar way as Haraway (2008) and others have done in the wake of Mary Louise Pratt's influential writings. She understands contact zones as "social spaces where cultures meet, clash, and grapple with each other, often in contexts of highly asymmetrical relations of power" (Prat 1991, page 34).

My suggestions to slow down abstractions may seem utopian and in tension with the fast-paced funding and reward structures of what Stengers (2011b) calls the knowledge economy, but they can work under certain conditions. From participants they demand commitment, patience, openness to being challenged and the willingness to experiment and accept the risk of failure. Meeting these demands will be easier when there is extensive time for dialogue and participants trust each other. Projects in which participants from different disciplinary and research backgrounds meet each other for one or a few days at specified intervals won't suffice; considerably longer periods of intense joint activity will need to be written into research designs. Having a long-term strategy of collaboration beyond a single project will also help. As far as finance is concerned, there are many opportunities to obtain funding for capacity building from national and EU agencies and charities that can be used to develop contact zones for the slowing down of abstractions. Depending on restrictions on that capability building funding, follow-up grants can be secured to consolidate contact zones.

\section{Nexus and Geography}

Commonalities and differences between Transition Studies and nexus research have been identified in previous sections. Collectively they imply that human geographers interested in the nexus find themselves in an oikos where obligations, requirements and abstractions are even more diverse and replete with contrasts, tensions and opportunities to make a difference than for disciples working on sustainability transitions. It is yet unclear what this means for the diffusion of concepts, logics, methods and practices from Human Geography into nexus research. Time will tell what will be abstracted from the political ecology conceptualisation of nexus-related processes by Williams et al. (2014) or from Cairns and Kryzwoszynska's (2016) discourse analysis of nexus as a buzzword in resource debates in the UK - to name but two examples of significant contributions to geographical scholarship on the nexus. Nonetheless, partial inheritance and problematic simplifications in (future) research outside Geography as well as asymmetrical exchange of insights between disciplines and epistemic communities are distinct possibilities.

To my mind, these possibilities should be borne in mind in the development of a nexus research agenda for Human Geography. Understanding the place-specific and multi-scalar nature of the interconnections of water, energy, food, land and climate should certainly be a major research priority. The same holds for research that critically analyses the discourse and genealogy of nexus thinking, develops epistemologically diverse understandings of the nexus using a plurality of methods, and seeks to harness the potential of ontological frictions in nexus processes. Yet, if asymmetrical exchange of concepts, ideas and methods across disciplines, epistemic communities 
and research fields and fragmenting pluralism are seen as undesirable, then a slowing down of reasoning will be needed. ${ }^{8}$

The creation of durable contact zones to scrutinise modes of abstraction to turn matters-of-fact into matter-of-concern may be useful for nexus research too, but the approach suggested for research on transitions will need to be adapted. For one, it will be important to involve the thinking and colleagues from Physical Geography where the nexus has yet to be embraced as a key research focus. The challenges of collaborating across the human/physical divide within the discipline are well-known but certainly not insurmountable (see, for instance, Lane et al. 2011). The value of collaboration lies not only in the concepts, ideas, logics and methods physical geographers have to offer but also in the mediating role they can fulfil between human geographers and natural scientists beyond Geography in the creation of contact zones for experimentation with alternative modes of abstraction.

Compared to the transition case, geographers may have to devote greater effort to drawing attention to elements that are often excluded in nexus research. As Wichelns (2017, page 120) has observed " $[\mathrm{w}]$ ith regard to agriculture, the water-energy-food nexus is largely silent on issues pertaining to other critical inputs, such as land, labour, capital, seeds, plant nutrients, and farm chemicals. The nexus also does not address issues involving land tenure, financial credit, and extension services." Ideas from various approaches, from Hägerstrand's (1976) time-geography to recent materialisms in Cultural Geography, can be introduced to non-geographers as potentially useful to their thinking. At the same time, geographers may have to be more explicit and reflexive about their own reasoning, given that many nexus researchers will lack the familiarity with social theory that is fairly common across Transition Studies. Thus, the for most geographers uncontentious ideas that the 'metabolism' of energy, water or food is conditioned by capitalism or that spatiotemporally contingent power relations (re)configure forms of rule, governance, hegemony and consensus (cf. Ekers and Loftus 2008; Williams et al. 2015) will need to be worked through carefully in contact zones. The same may hold for the idea from the wider social sciences that scientific representations emerge from all sorts of power/knowledge dynamics that are refracted and mediated by equally heterogeneous material techniques and instruments.

Human geographers should also dedicate extra effort to slowing down the abstractions enacted by mathematical and computer modelling. This is not only because such modelling plays a very dominant role in interdisciplinary nexus research, but also because over the past 15-20 years Geography has seen the rise of new and alternative modes of abstraction using computer modelling and quantitative data. Examples are work on critical and qualitative GIS (Schuurman 2000; Cope and Elwood 2009), on critical quantitative geography (Kwan and Schwanen 2009), on critical studies of big data (Kitchin 2014; Shelton et al. 2016) and on participatory modelling as knowledge coproduction (Lane et al. 2011). Such work can aid in bringing more reflexivity to nexus modelling research and reorient it towards questions, experiences and interplays of values that are easily abstracted away (cf. Stengers 2011b; Lane 2017). Building on earlier work (Schwanen and Kwan 2009), I see several ways in which this can be achieved. Recognised lacunae in much interdisciplinary nexus research (Allouche et al. 2015; Leck et al. 2015) can be addressed by co-developing models of nexus processes to raise questions about justice - who gains? Who loses? How? - and by incorporating different types of knowledge and understandings. Text, video and other materials could be incorporated into nexus modelling so that the differentiated and complex everyday experiences of local populations can be addressed as problems in nexus research and thinking. Geographers can also help to bring out the situatedness and spatiotemporal contingent nature of modelling research and thus co-construct different modes of interpreting and generalising model results. Finally, they can aid in the experimental deployment of models so that they function as technologies for thinking differently, opening up alternative understandings and engineering 
surprising ideas and hypotheses that could not have been anticipated beforehand. Slowing down modelling won't be easy and Stengers's prescription that the idiotic be accommodated in the crafting of contact zones needs to be heeded but the use of models to diffuse insights from Geography into interdisciplinary nexus research may resonate beyond the discipline as an analytically rigorous, efficient, and relatively easy-to-understand way of communication.

\section{Conclusion}

More than ever is Geography surrounded by interdisciplinary movements claiming expertise with regard to the interconnections among nature, society and technology. Its practitioners are also increasingly expected to collaborate across disciplinary boundaries. These developments bring many benefits to Geography and provide opportunities for its concepts, ideas, logics and methods to be taken up beyond its boundaries. However, there is a genuine risk that what many geographers consider cutting-edge thinking gets excluded or overly simplified when encountered by researchers who neither are trained nor self-identify as geographers. Whilst differences in language between disciplines, epistemic communities and research fields go some way to explaining this risk, rigidity in the modes of abstraction - and, related to these, obligations and requirements - that prevail in specific disciplines, epistemic cultures and research fields are equally if not more important. This means that many of the widely promoted ideas about how modes of interdisciplinary research oriented at integration across disciplines, epistemic cultures or research may be insufficient to generate research on the interconnections among nature, society and technology that is 'transgeographical' - at once transdisciplinary and widely seen as world-leading within Geography as a discipline. Other strategies and approaches that are flexible, emergent, open-ended and attentive to what Stengers and others call the idiotic may be needed. The slowing down of abstraction as elaborated in this article may play a useful role in harnessing Geography's contributions to thinking, imagining and reinventing the inevitably place-specific interconnections among nature, science and technology in an increasingly transdisciplinary world.

\section{Notes}

1. I am grateful to one of the reviewers of an earlier version of this manuscript for bringing out this point much more clearly than I did.

2. The ways such research is shaped by funding mechanisms, stakeholder interactions, the changed role and governance of universities in late capitalism and so forth are deliberately not considered here.

3. These constraints should be understood as non-deterministic; they steer and shape action but do not produce inevitable, certain effects.

4. A point would only be appropriate if there is no uncertainty or controversy about a particular response, a situation that is likely rare.

5. This mode of abstraction may not be productive and creative to many geographers but it can be generative from the perspective of researchers from other disciplines and research fields may find it (very) generative and inspiring. The generative capacities of abstraction are not only relational but also relative; claims about those capacities need to be accompanied by discussion of the question for whom/what and in what ways.

6. Stengers (2005b) derives the figure of the idiot from Deleuze and Guattari (1994) as someone who challenges the consensual interpretation of events because their (in)action is incommensurable with those events.

7. My proposal is informed by two sets of experiences. One relates to my ongoing interest in habit change, the other to research project on the interdependence of transport and social exclusion. In that project we combined the ideas and concerns of researchers from different disciplinary and research backgrounds through an emergent and open-ended process. 
8. Another reason for slowing down nexus research is that much of it adheres to what Stengers (2011b) calls the knowledge economy and can be considered to "progress in its own groove" (Whitehead 1967[1925], page 197) with limited interrogation of its modes of abstraction, the kinds of problem it addresses or how it seeks to solve those.

\section{Acknowledgements}

An earlier version of this paper was presented as the Transactions of the Institute of British Geographers Plenary Lecture at the 2016 Annual International Conference of the RGS/IBG. I am grateful for the comments made by the two discussants during the conference session, Jenny Pickerill and Zarina Patel, as well as by two anonymous reviewers and Robyn Dowling. The research on which I reflect on the paper was made possible by RCUK (grant number EP/K011790/1).

\section{References}

Adams W M 2016 Do you speak lion? Science 3536303 867-8

Affolderbach J and Schultz C 2016 Mobile transitions: exploring synergies for urban sustainability research Urban Studies 63 1942-57

Aiken G T 2012 Community transitions to low carbon futures in the Transition Towns Network (TTN) Geography Compass 6 89-99

Aiken G T 2016 Prosaic state governance of community low carbon transitions Political Geography $5520-29$

Allouche J, Middleton C and Gyawali D 2015 Technical veil, hidden politics: Interrogating the power linkages behind the nexus Water Alternatives 8 610-26

Arthur W B 2011 The nature of technology: what it is and how it evolves The Free Press, New York

Avelino F and Rotmans J 2009 Power in transition: an interdisciplinary framework to study power in relation to structural change European Journal of Social Theory 12 543-69

Barnes T J and Sheppard E 2010 'Nothing includes everything': towards engaged pluralism in Anglophone economic geography Progress in Human Geography 34, 193-214

Barr S and Pollard J 2017 Geographies of transition: narrating environmental activism in an age of climate change and 'peak oil' Environment and Planning A 47 47-64

Barry A, Born G and Weskalnys G 2008 Logics of interdisciplinarity Theory, Culture and Society 37 20-49

Bazilian M, Rogner H, et al 2016 Considering the energy, water and food nexus: towards an integrated modelling approach Energy Policy 39 7896-906

Bernstein R J 1988 Pragmatism, pluralism and the healing of wounds Proceedings and Addresses of the American Philosophical Association 63 5-18 
Bracken L J and Oughton E A 2006 'What do you mean?' The importance of language in developing interdisciplinary research Transactions of the Institute of British Geographers 31 371-82

Brenner N ed 2013 Implosions/explosions: towards a study of planetary urbanization Jovis, Berlin

Bridge G, Bouzarowski S Bradshaw M and Eyre N 2013 Geographies of energy transition: Space, place and the low-carbon economy Energy Policy 53 331-340

Brown G, Kraftl P, Pickerill J and Upton C 2012 Holding the future together: towards a theorisation of the spaces and times of transition Environment and Planning A 44 1607-23

Brown R R, Deletic A and Wong T H F 2015 Interdisciplinarity: how to catalyse collaboration Nature 525 315-7

Bulkeley H 2010 Cities and governing of climate change Annual Review of Environment and Resources 35 229-53

Bulkeley H and Castán Broto V 2013 Government by experiment? Global cities and the governing of climate change Transactions of the Institute of British Geographers 38 361-75

Bulkeley $\mathrm{H}$ et al 2016 Urban living labs: governing urban sustainability Current Opinion in Environmental Sustainability 22 23-17

Bulkeley H, Castán Broto V, Hodson M and Marvin S 2010 Cities and low carbon transitions Routledge, London

Bulkeley H, Castán Broto V and Maassen A 2014 Low-carbon transitions and the reconfiguration of urban infrastructure Urban Studies 51 1471-86.

Cairns R and Krzywoszynska A 2016 Anatomy of a buzzword: The emergence of 'the water-energyfood nexus' in UK natural resource debates Environmental Science \& Policy 64 164-70

Castree N 2016 Geography and the new social contract for global change research Transactions of the Institute of British Geographers 41 328-47

Castree N, Adams W M, et al 2014 Changing the intellectual climate Nature Climate Change 4 763-8

Chang Y, Li G, Yao Y, Zhang L and Yu C 2016 Quantifying the water-energy-food nexus: current status and trends Energies 965

Chatterton P 2016 Building transitions to post-capitalist urban commons Transactions of the Institute of British Geographers 41 403-15

Chatterton P and Pickerill J 2010 Everyday activism and transitions towards post-capitalist worlds Transactions of the Institute of British Geographers 35 475-90

Coenen L, Benneworth P and Truffer B 2012 Toward a spatial perspective on sustainability transitions Research Policy 41 968-79 
Coenen L and Hansen T 2015 The geography of sustainability transitions: Review, synthesis and reflections on an emergent research field Environmental Innovations and Societal Transitions 17 92-109

Coenen L, Raven R and Verbong $\mathbf{G} 2010$ Local niche experimentation in energy transitions: a theoretical and empirical exploration of proximity advantages and disadvantages Technology in Society 32 295-302

Cope M and Elwood S 2009 Qualitative GIS: a mixed methods approach Sage, London

Cote $\mathbf{M}$ and Nightingale A J 2011 Resilience thinking meets social theory: Situating social change in socio-ecological systems (SES) research Progress in Human Geography 36 475-89

Deleuze G and Guattari F 1994 What is philosophy? Columbia University Press, New York

Despret V 2004 Our emotional makeup: ethnopsychology and selfhood Other Press, New York

Donaldson A, Ward N and Bradley S 2010 Mess among disciplines: interdisciplinarity in environmental research Environment and Planning A 42 1531-36

Ekers M and Loftus A 2008 The power of water: developing dialogues between Foucault and Gramsci Environment and Planning D: Society and Space 26 698-718

Endo A, Burnett K, et al 2015 Methods of the water-energy-food nexus Water 7 5806-30

Evans J Karvonen A and Raven R eds 2016 The experimental city Routledge, London

Faeth P and Hanson L 2016 A research agenda for the energy, water, land, and climate nexus Journal of Environmental Studies and Sciences 6 123-26

Feola G and Nunes R 2014 Success and failure of grassroots innovations for addressing climate change: the case of the Transition Movement Global Environmental Change 24 232-50

Foran T 2015 Node and regime: Interdisciplinary analysis of water-energy-food nexus in the Mekong region Water Alternatives 8 655-74

Foucault M 1980 Truth and power in Gordon C ed Power/knowledge: Selected interviews \& other writings 1972-1977 by Michel Foucault Pantheon Books, New York 109-33

Foucault M 1985 The use of pleasure: the history of sexuality, volume 2 Penguin Books, London

Foucault M 2010 The government of self and others: lectures at the Collège de France 1982-1983 Palgrave Macmillan, Houndsmills

Funtowicz S O and Ravetz J R 1993 Science for the post-normal age Futures 25 739-55

Galison P 1997 Image and logic: a material culture of microphysics University of Chicago Press, Chicago

Galison P 2010 Trading with the enemy in Gorman M E ed Trading zones and interactional expertise: creating new kinds of collaboration MIT Press, Cambridge, MA 25-52 
Geels F W 2002 Technological transitions as evolutionary reconfiguration processes: a multi-level perspective and a case-study Research Policy 31 1257-74

Geels F W 2004 From sectoral systems of innovation to socio-technical systems: insights about dynamics and change from sociology and institutional theory Research Policy 33 897-920

Geels F W 2010 The role of cities in technological transitions - analytical clarifications and historical examples in Bulkeley H, Castán Broto V, Hodson M and Marvin S ed Cities and low carbon transitions Routledge, New York 13-28

Geels F W 2014 Regime resistance against low-carbon transitions: introducing politics and power into the multi-level perspective Theory, Culture \& Society 31 21-40

Geels F W, Kern F, Fuchs G, et al 2016 The enactment of socio-technical pathways: A reformulated typology and a comparative multi-level analysis of the German and UK low-carbon electricity transitions (1990-2014) Research Policy 45 896-913

Geels F W and Schot J 2007 Typology of sociotechnical transition pathways Research Policy 36 399417

Gorman M E ed 2010 Trading zones and interactional expertise: creating new kinds of collaboration MIT Press, Cambridge, MA

Hansen T and Coenen L 2015 The geography of sustainability transitions: review, synthesis and reflections on an emergent research field Environmental Innovation and Societal Transitions 17 92-109

Hansen U E and Nygaard I 2013 Transnational linkages and sustainable transitions in emerging countries: Exploring the role of donor Environmental Innovation and Societal Transitions 8 1-19

Haraway D J 2008 When species meet University of Minnesota Press, Minneapolis, MN

Harvey D 2009 Cosmopolitanism and the geographies of freedom Columbia University Press, New York

Hägerstrand T 1976 Geography and the study of interaction between nature and society Geoforum 7 329-34

Hodson M 2008 Old industrial regions, technology, and innovation: tensions of obduracy and transformation Environment and Planning A 40 1057-1075

Hodson M and Marvin S 2009 Cities mediating technological transitions: understanding visions, intermediation and consequences Technology Analysis \& Strategic Management 21 515-534

Hodson M and Marvin S 2010 Can cities shape socio-technical transitions and how would we know if they were? Research Policy 39 477-85

Hoff H 2011 Understanding the Nexus - Background Paper for the Bonn 2011 Conference: The Water, Energy and Food Security Nexus Stockholm Environment Institute, Stockholm 
Hoogma R, Kemp R, Schot J and Truffer B 2002 Experimenting for sustainable transport: the approach of strategic niche management Spon Press, London

Hossein M 2016 Grassroots innovation: a systematic review of two decades of research Journal of Cleaner Production 37 973-81

Howarth C and Monasterolo I 2016 Understanding barriers to decision making in the UK energyfood-water nexus: The added value of interdisciplinary approaches Environmental Science \& Policy 61 53-60

Jahn T, Bergmann T and Keil F 2012 Transdisciplinarity: between mainstream and marginalization Ecological Economics 79 1-10

Kemp R, Loorbach D and Rotmans J 2007 Transition management as a model for managing processes of co-evolution towards sustainable development International Journal of Sustainable Development \& World Ecology 14 78-91

Kitchin R 2014 The data revolution: big data, open data, data infrastructures and their consequences Sage, London

Klenk N and Meehan K 2015 Climate change and transdisciplinary science: problematizing the integration imperative Environmental Science \& Policy 54 160-67

Knorr Cetina K 2009 Epistemic cultures: how the sciences make knowledge Harvard University Press, Cambridge, MA

Kwan M-P and Schwanen 2009 Quantitative revolution 2: the critical (re)turn The Professional Geographer 61 283-91

Lane S N 2017 Slow science, the geographical expedition, and Critical Physical Geography The Canadian Geographer 61 84-101

Lane S N, et al 2011 Doing flood risk science differently: an experiment in radical scientific method Transactions of the Institute of British Geographers 36 15-36

Lang D J, et al 2012 Transdisciplinary research in sustainability science: practice, principles, and challenge Sustainability Science 7(S1) 25-43

Latour B 2008 What is the style of matters of concern? Van Gorcum, Assen

Lawhon and Murphy J T 2012 Socio-technical regimes and sustainability transitions: Insights from political ecology Progress in Human Geography 36 354-78

Leck H, Conway D, Bradshaw M and Rees J 2015 Tracing the water-energy-food nexus: description, theory and practice Geography Compass 9 445-60

Lefebvre H 1991 The production of space Blackwell, Malden, MA

Longhurst N 2015 Towards an 'alternative' geography of innovation: alternative milieu, sociocognitive protection and sustainability experimentation Environmental Innovations and Societal Transition 17 183-97 
Loorbach D, Frantzeskaki N and Avelino F 2017 Sustainability transition research: transforming science and practice for societal change. Annual Review of Energy and Resources 42 in press

Loorbach D, Wittmayer, J M, et al 2016 Governance of urban sustainability transitions: European and Asian experiences Springer, Tokyo

Lovell H, Owens S and Bulkeley H 2009 Converging agendas? Energy and climate change policies in the UK Environment and Planning C: Government and Policy 27 90-109

Marzano M, Carss D N and Bell S 2006 Working to make interdisciplinarity work: investing in communication and interpersonal relationships Journal of Agricultural Economics 57 185-97

Mason K and Whitehead M 2012 Transition urbanism and the contested politics of ethical place making Antipode 44 493-516

Massey D 2005 For space Sage, London

McCann E and Ward K 2013 A multi-disciplinary approach to policy transfer research: geographies, assemblages, mobilities and mutations Policy Studies 34 2-18

McCann E, Roy A and Ward K 2013 Assembling/worlding cities Urban Geography 34 581-89

McCormack D P 2012 Geography and abstraction: towards an affirmative critique Progress in Human Geography 36 715-34

McCormick K, Anderberg S, Coenen L and Neij L 2013 Advancing sustainable urban transformation Journal of Cleaner Production 50 1-11

Meadowcroft J 2005 Environmental political economy, technological transitions and the state New Political Economy 10 479-98

Michael M 2012 "what are busy doing?": Engaging the idiot Science, Technology \& Human Values 37 528-554

Mohtar R H and Langford R 2016 Present and future of the water-energy-food nexus and the role of the community of practice Journal of Environmental Studies and Sciences 6 192-99

Moulaert F, Swyngedouw E, Martinelli F and González S eds 2010 Can neighbourhoods save the city? Community development and social innovation Routledge, London

Mouffe C 2005 On the political Routledge, Abingdon

Mountz A, et al 2015 For slow scholarship: a feminist politics of resistance through collective action in the neoliberal university ACME: An International Journal for Critical Geographies 14 1235-59

Murphy J T 2015 Human geography and socio-technical transition studies: promising intersections Environmental Innovation and Societal Transitions 17 73-91

Nevens F, Frantzeskaki N, Gorissen L and Loorbach D 2013 Urban Transition Labs: co-creating transformative action for sustainable cities Journal of Cleaner Production 50 122-33 
Newell P and Mulvaney D 2013 The political economy of the 'just' transition The Geographical Journal 179 132-140

Newell P and Phillips J 2016 Neoliberal energy transitions in the South: Kenyan experiences Geoforum 74 39-48

Nowotny H, Scott P and Gibbons M 2003 Introduction: 'mode 2' revisited: the new production of knowledge Minerva 41 179-94

Osborne P 2015 Problematizing disciplinarity, transdisciplinary problematics Theory, Culture and Society 35 3-35

Pittock J, Hussey K and McGlennon S 2013 Australian climate, energy and water policies: conflicts and synergies Australian Geographer 44 3-22

Pratt M L 1991 Arts of the contact zone Profession 1991 33-40

Rabinow P 1994 Polemics, politics and problematizations: an interview with Michel Foucault in Rabonow P ed Essential works of Foucault 1954-1984 Volume 1 - Ethics: subjectivity and truth Penguion Books, London 111-9

Raven R, Kern F, et al 2016 The politics of innovation spaces for low-carbon energy: introduction to the special issue Environmental Innovation and Societal Transitions 18 101-10

Rip A and Kemp R 1998 Technological change in Rayner S and Malone E L eds Human Choice and Climate Change Volume 2 Battelle Press, Columbus, OH 327-99

Robinson J 2006 Ordinary cities: between modernity and development Routledge, London

Rock M, Murphy J T, et al 2009 A hard slog, not a leap frog: Globalization and sustainability transitions in developing Asia Technological Forecasting and Social Change 76 241-54

Romijn H, Raven R and de Visser I 2010 Biomass energy experiments in rural India: Insights from learning-based development approaches and lessons for Strategic Niche Management Environmental Science \& Policy 13 326-38

Rotmans J, Kemp R and M van Asselt 2001 More evolution than revolution: transition management in public policy Foresight 3 15-31

Rotmans J and Loorbach D 2009 Complexity and transition management Journal of Industrial Ecology 13 184-96

Roy A 2009 The 21st-century metropolis: new geographies of theory Regional Studies 43 819-30

Roy A and Ong A eds 2011 Worlding cities: Asian experiments and the art of being global Blackwell, Malden, MA

Schuurman N 2000 Trouble in the heartland: GIS and its critics in the 1990s Annals of the Association of American Geographers 24 569-90 
Schwanen T 2015 The bumpy road toward low-energy urban mobility: case studies from two UK cities Sustainability 7 7086-111

Schwanen T 2016 Innovations to transform personal mobility in Hopkins D and Higham J eds Low Carbon Mobility Transitions Goodfellow Publishers, Oxford 206-19

Schwanen T and Kwan M-P 2009 "Doing" critical geographies with numbers The Professional Geographer 61 459-64

Sengers F and Raven R 2015 Toward a spatial perspective on niche development: The case of Bus Rapid Transit Environmental Innovation and Societal Transitions 17 166-82

Seyfang G and Smith A 2007 Grassroots innovations for sustainable development: towards a new research and policy agenda Environmental Politics 164 584-603

Shelton T, Poorthuis A and Zook M 2016 Social media and the city: Rethinking urban socio-spatial inequality using user-generated geographic information Landscape and Urban Planning 142 198211

Sheppard E, Leitner H and Maringanti A 2013 Provincialising global urbanism: a manifesto Urban Geography 34 893-90

Shove E and Walker G 2007 CAUTION! Transitions ahead: politics, practice and sustainable transition management Environment and Planning A 39 763-70

Smith A and Raven R 2012 What is protective space? Reconsidering niches in transitions to sustainability Research Policy 41 1025-36

Stengers I 2005a Introductory notes on an ecology of practice Cultural Studies Review 11 183-96

Stengers I 2005b The cosmopolitical proposal in Latour B and Weibel P eds Making things public MIT Press, Cambridge, MA 994-1004

Stengers I 2010a Cosmopolitics I University of Minnesota Press, Minneapolis, MN

Stengers I 2010b Cosmopolitics // University of Minnesota Press, Minneapolis, MN

Stengers I 2011a Comparison as a matter of concern Common Knowledge 17 48-63

Stengers I 2011b "Another science is possible!": a plea for slow science Vrije Universiteit Brussel, available at: http://we.vub.ac.be/aphy/sites/default/files/stengers2011 pleaslowscience.pdf (last accessed 28 January 2017)

Stirling A 2015 Developing 'nexus capabilities': towards transdisciplinary methodologies Available at: http://www.thenexusnetwork.org/ (last accessed 7 December 2016)

Temenos C, Nikolaeva A, et al 2017 Theorising mobility transitions: an interdisciplinary conversation Transfers 7 113-29

Thrift N 2008 Non-representational theory: space, politics, affect Routledge, London 
Truffer B 2008 Society, technology, and region: contributions from the social study of technology to economic geography Environment and Planning A 40 966-85

Urry J 2012 Climate change and society Polity, Cambridge

Walker G and Cass N 2007 Carbon reduction, 'the public' and renewable energy: engaging with socio-technical configurations Area 39 458-69

Wassen M J and Hekkert M P 2015 Interdisciplinary: two more principles Nature 526323

WEF (World Economic Forum) 2011 Water Security: The Water-Food-Energy-Climate Nexus Island Press, Washington DC

Whatmore S J 2013 Earthly powers and affective environments: an ontological politics of flood risk Theory, Culture \& Society 30 33-50

Whitehead A N 1967[1925] Science and the Modern World The Free Press, New York

Whitehead A N 1968[1938] Modes of Thought The Free Press, New York

Whitehead A N 19771929] Process and Reality corrected edition The Free Press, New York

Wieczorek A J, Raven R and Berkhout F 2015 Transnational linkages in sustainability experiments: a typology and the case of solar photovoltaic energy in India Environmental Innovation and Societal Transitions 17 149-65

Wichelns D 2017 The water-energy-food nexus: is the increasing attention warranted, from either a research or policy perspective? Environmental Science \& Policy 69 113-23

Williams J, Bouzarovski S and Swyngedouw E 2014 Politicising the nexus: nexus technologies, urban circulation, and the coproduction of water-energy Nexus Network Think Piece Series

Wolfram M 2016 Cities shaping grassroots niches for sustainability transitions: conceptual reflections and an exploratory case study Journal of Cleaner Production DOI:

10.1016/j.clepro.2016.08.044

Yang Y C E, Wi S, et al 2016 The future nexus of the Brahmaputra River Basin: Climate, water, energy and food trajectories Global Environmental Change 37 16-30 
Table 1: Interdisciplinary research: barriers and facilitators

\begin{tabular}{|c|c|}
\hline Barriers & Facilitators \\
\hline \multicolumn{2}{|l|}{ Wider organisational field \& institutions } \\
\hline Research agendas & $\begin{array}{l}\text { Involvement of academics from different disciplines \& non-academic stakeholders in identification of research } \\
\text { priorities (substantive topics, methodological developments) and in framing of issues }\end{array}$ \\
\hline Inadequate funding & $\begin{array}{l}\text { Collaboration among funding agencies; Longer-term, transdisciplinary funding programmes; Evaluation panels with } \\
\text { experts from different disciplines and end users }\end{array}$ \\
\hline Reward structures & $\begin{array}{l}\text { Broad performance indicators (beyond publication portfolios) in funding allocation and research evaluation; Champion } \\
\text { impacts beyond academia }\end{array}$ \\
\hline Researcher capacity & $\begin{array}{l}\text { Training of interdisciplinary students \& early-career researchers; Organisation of summer schools, seminars, workshops } \\
\text { and other platforms for cross-disciplinary dialogue }\end{array}$ \\
\hline Career trajectories & Change to promotion structures \& pathways; Mentorship \\
\hline Expectations beyond academia & $\begin{array}{l}\text { Engagement of non-academic stakeholders \& end users in agenda setting, funding decisions, research evaluation; } \\
\text { Effective communication with non-academic stakeholders \& end users }\end{array}$ \\
\hline Data availability, access and management & $\begin{array}{l}\text { Appropriate infrastructures; Promotion and use of publicly available data; Reliance on open source software; } \\
\text { Clarification of intellectual rights }\end{array}$ \\
\hline \multicolumn{2}{|l|}{ Research programs, projects \& teams } \\
\hline Differences in expectations \& purpose & $\begin{array}{l}\text { Frequent \& effective communication; Establishment of common goals; Identification of object of study; Participation of } \\
\text { non-academic stakeholders in all phases }\end{array}$ \\
\hline $\begin{array}{l}\text { Lack of common understandings, concepts \& } \\
\text { language }\end{array}$ & $\begin{array}{l}\text { Frequent \& effective communication; Reflexive \& recursive research designs; Clear definition of concepts and terms; } \\
\text { Identification of relevant temporal and spatial scales }\end{array}$ \\
\hline Lack of trust across disciplinary boundaries & $\begin{array}{l}\text { Frequent \& effective communication; Spatial proximity of researchers; Diversity of team members w.r.t. career stage, } \\
\text { gender, ethnicity, discipline \& function; democratic leadership; Conflict resolution }\end{array}$ \\
\hline $\begin{array}{l}\text { Hierarchies in types of expertise; social science } \\
\& \text { humanities as 'add-on' }\end{array}$ & Reflexive \& recursive research designs; 'Frontloading' social science \& humanities \\
\hline
\end{tabular}

Based on: Bracken and Oughton (2006); Marzano et al. (2006); Jahn et al. (2012); Lang et al. (2012); Brown et al. (2015); Adams (2016); Wassen and Hekkert (2015); Klenk and Meehan (2016) 
Table 2: Abstraction from selected geographical publications on sustainability transitions beyond the discipline

\begin{tabular}{|c|c|c|c|}
\hline Authors and year of publication & Journal & Citation count $^{1}$ & Inheritance \\
\hline Hodson and Marvin (2010) & Research Policy & 336 & $\begin{array}{l}\text { Wide uptake and significant influence }{ }^{2} \text { across various constituencies, } \\
\text { including transition scholars in innovation studies, but especially among } \\
\text { scholars interested in urban transformations and urban studies }\end{array}$ \\
\hline Lawhon and Murphy (2012) & Progress in Human Geography & 171 & $\begin{array}{l}\text { Reasonably wide uptake and significant influence }{ }^{2} \text { across various } \\
\text { constituencies, including transition scholars in innovation studies, } \\
\text { possibly because of its generic nature (not focused on cities) and limited } \\
\text { use of discipline-specific vocabulary }\end{array}$ \\
\hline Bulkeley and Castán Broto (2013) & $\begin{array}{l}\text { Transactions of the Institute } \\
\text { of British Geographers }\end{array}$ & 257 & $\begin{array}{l}\text { Wide uptake and significant influence }{ }^{2} \text { across various constituencies but } \\
\text { mostly among geographers, sustainability scientists and those interested } \\
\text { in urban transformations, less so among transitions scholars in } \\
\text { innovation studies }\end{array}$ \\
\hline Newell and Mulvaney (2013) & The Geographical Journal & 55 & $\begin{array}{l}\text { Some uptake and influence across various constituencies, including } \\
\text { geographers and among several leading transition scholars, but mostly } \\
\text { in the peripheries of the transitions literature }\end{array}$ \\
\hline Bulkeley et al. (2014) & Urban Studies & 65 & $\begin{array}{l}\text { Mostly taken up in geographical research and interdisciplinary research } \\
\text { on the role of cities in sustainability transition, less so among transition } \\
\text { scholars in innovation studies }\end{array}$ \\
\hline
\end{tabular}

${ }^{1}$ Google Scholar, 29 January 2017

${ }^{2}$ Here understood as having a direct, albeit it subjectively identified, effect on the thinking or research practice of the papers in which the publication is referenced 


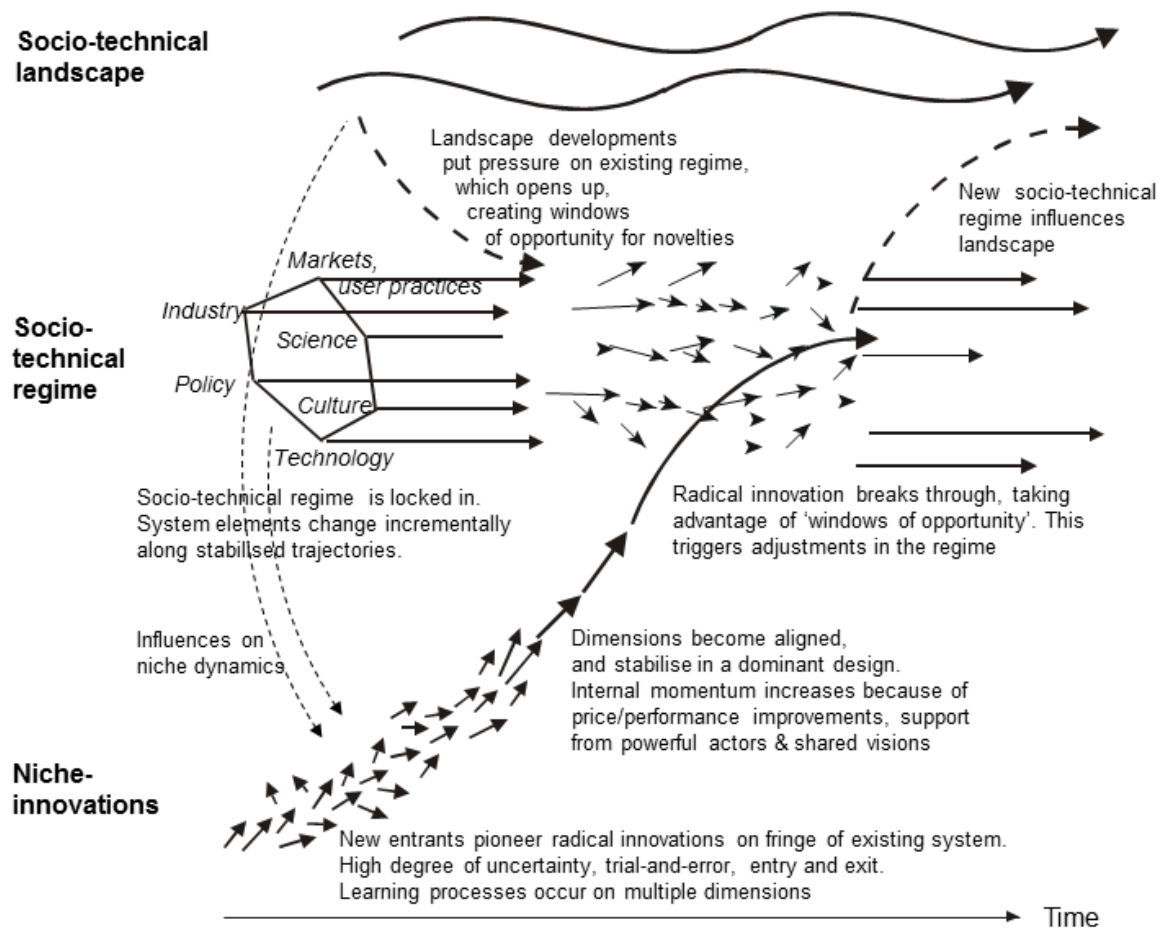

Figure 1: Multi-level perspective diagram (adapted from: Geels 2002) 


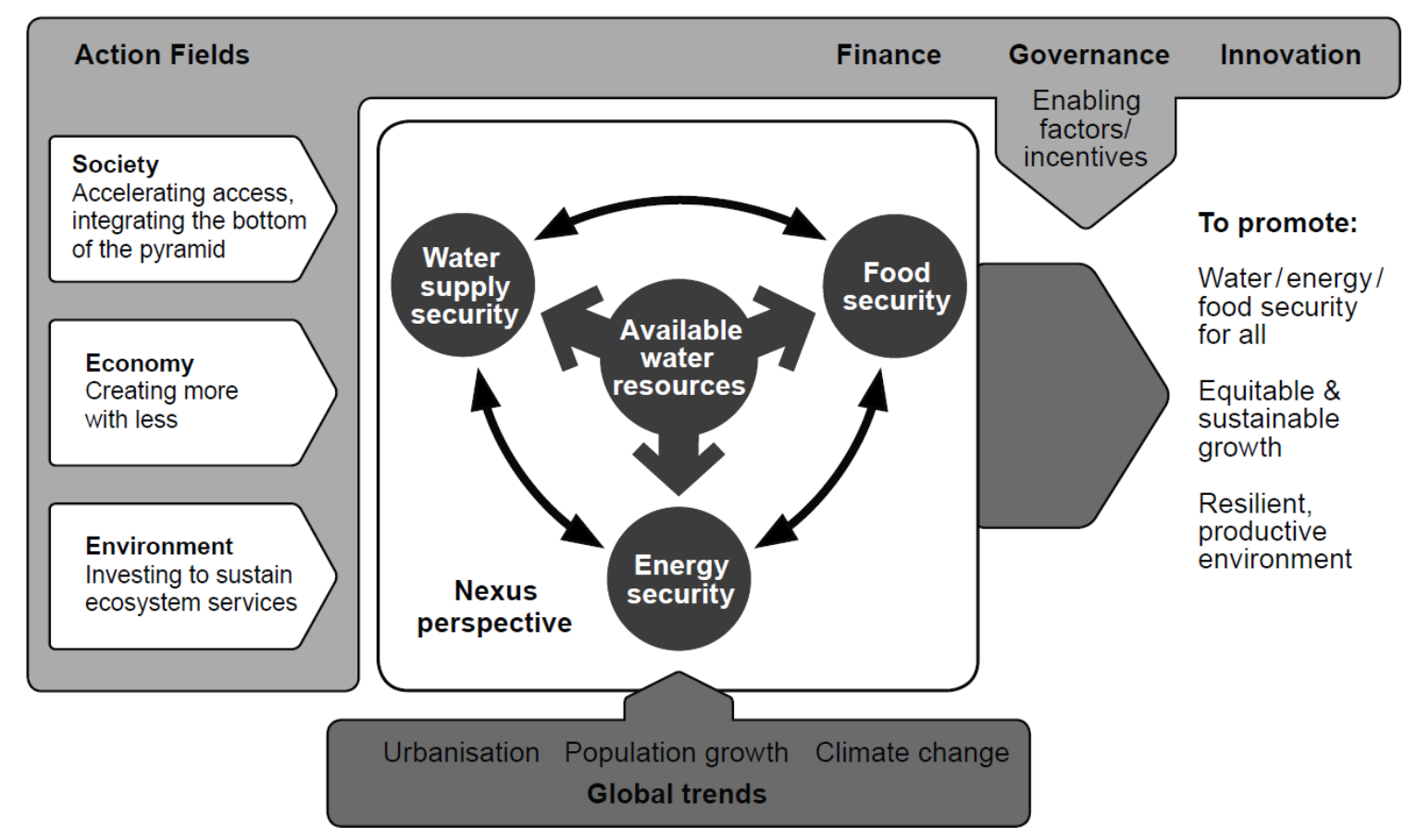

Figure 2: Water-energy-food nexus diagram (adapted from: Hoff 2011) 


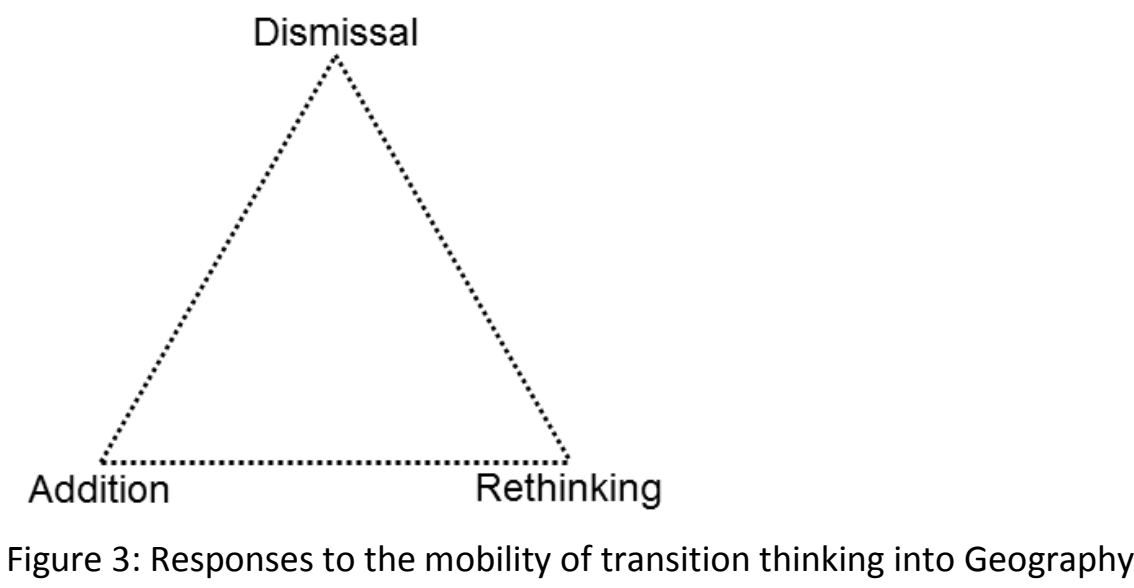




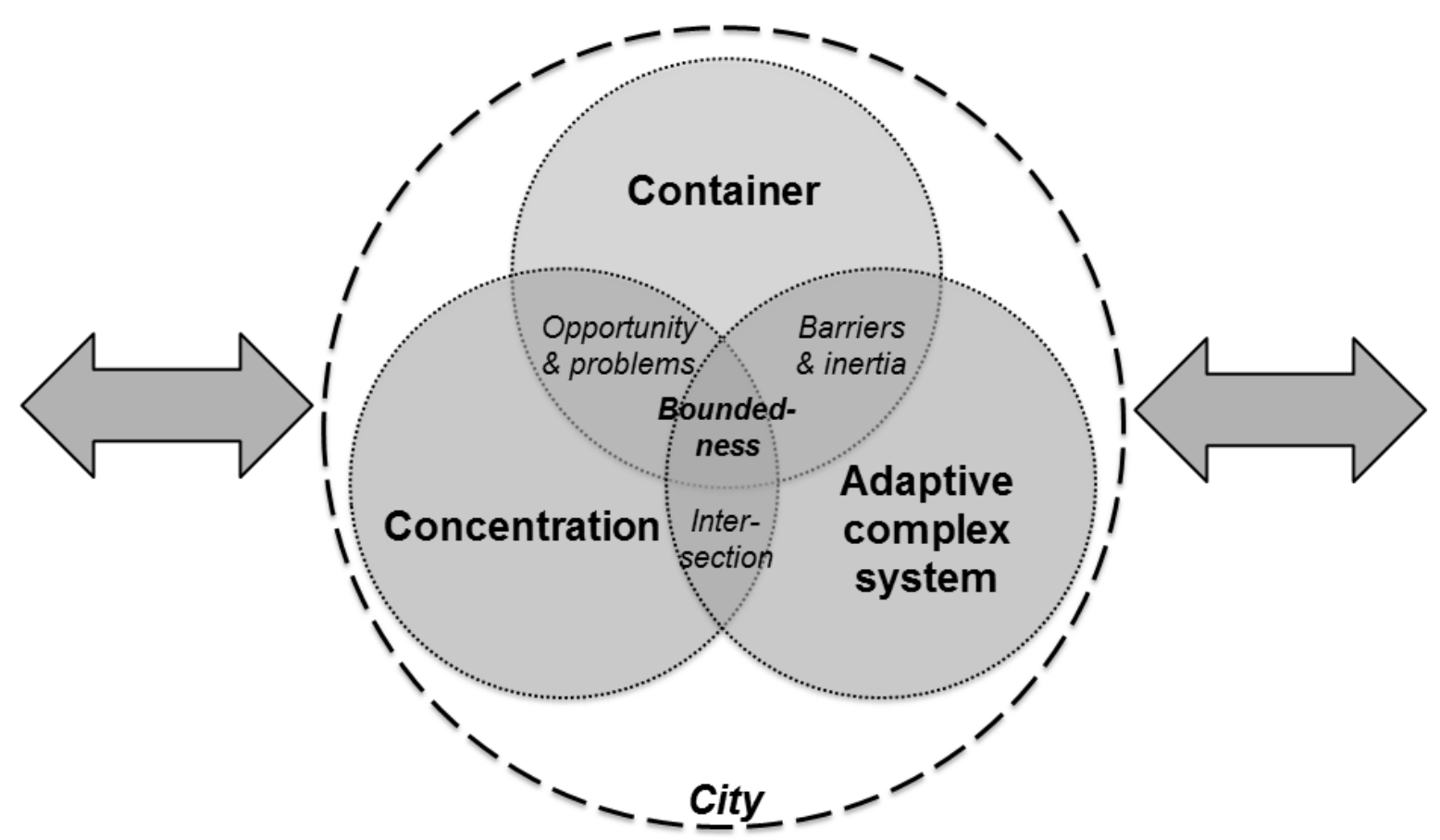

Figure 4: Versions of the city in the urban transitions literature 